\title{
Geologic map of the Lakeview 7.5' quadrangle, Riverside County, California
}

\author{
By D.M. Morton ${ }^{1}$ and J.C. Matti ${ }^{2}$ \\ Digital preparation by Rachel Alvarez ${ }^{1}$, and P.M. Cossette ${ }^{3}$
}

Prepared in cooperation with

CALIFORNIA DIVISION OF MINES AND GEOLOGY

and EASTERN MUNICIPAL WATER DISTRICT

Open-File Report OF 01-174

2001

Any use of trade, product, or firm names is for descriptive purposes only and does not imply endorsement by the U. S. Government. This database, identified as "Geologic map of the Lakeview 7.5' quadrangle, Riverside County, California " has been approved for release and publication by the Director of the USGS.

\section{U. S. DEPARTMENT OF THE INTERIOR}

U. S. GEOLOGICAL SURVEY

${ }^{1}$ Western Earth Surface Processes Team, U.S. Geological Survey

U.S. Geological Survey, Department of Earth Sciences, University of California, Riverside, CA 92521

${ }^{2}$ Western Earth Surface Processes Team, U.S. Geological Survey 920 Park Avenue, Tucson, AZ 85719

${ }^{3}$ U.S. Geological Survey

904 West Riverside Avenue, Spokane, WA 99201 


\section{TABLE OF CONTENTS}

Introduction

General

How to obtain paper plots

Database contents

Data package

Plot package

Other files

Software utilities

How to obtain the digital files

How to extract the geologic map database from the tar file

Digital database

PostScript plot files

Portable Document Format (.pdf) files

How to convert the ARC/INFO interchange (export) files

Digital geologic map specifications

Digital and geologic compilation of geologic map

Base map

Spatial resolution

Map accuracy standards

Database specifics

General

Lines

Polygons

Points

Overview of data table (.rel) contents

Coded, detailed, geologic data

Searching the database

References

Appendix I

\section{INTRODUCTION}

\section{General}

Open-File Report OF 01-174 contains a digital geologic map and map database of the Lakeview 7.5' quadrangle, Riverside County, California that includes:

1. ARC/INFO (Environmental Systems Research Institute, http://www.esri.com) version 7.2.1 double precision coverages of thevarious elements of the geologic map

2. A Postscript file to plot the geologic map on a topographic base, and containing a Correlation of Map Units diagram, and Description of Map Units

3. Portable Document Format (.pdf) files of:

a. This Readme; includes in Appendix I, data contained in lkvw_met.txt

b. The same graphic as plotted in 2 above. (Test plots from this .pdf do not produce 1:24,000-scale maps. Adobe Acrobat pagesize settings control map scale.)

This release includes features not found in most other digital geologic maps, in that all polygons, lines, and points in the coverage are encoded with detailed, comprehensive, contained in five INFO data tables (.rel) (see Matti and others, 1998a, 1998b, and 1998c for information on how the encoding may be accessed and utilized). No paper map is included in the Open-File report, but a PostScript plot file containing an image of the geologic map sheet, topographic base, Correlation of Map Units (CMU), and detailed Description of Map Units (DMU) is. Within the geologic map 
data package, map units are identified by standard geologic map criteria such as formation-name, age, and lithology. Even though this is an author-prepared report, every attempt has been made to closely adhere to the stratigraphic nomenclature of the U. S. Geological Survey. Descriptions of units can be obtained by viewing or plotting the .pdf file ( $3 \mathrm{~b}$ above) or plotting the postscript file ( $2 \mathrm{a}$ above). If roads in some areas, especially roads that parallel topographic contours, do not show well on plots of the geologic map, we recommend use of the USGS Lakeview 7.5' topographic quadrangle in conjunction with the geologic map.

This README file describes the digital data, such as types and general contents of files making up the database, and includes information on how to extract and plot the map and accompanying graphic file. Metadata information can be accessed at http://geo-nsdi.er.usgs.gov/cgi-bin/publication?map-of and is included in Appendix I, Readme.

\section{HOW TO OBTAIN PAPER PLOTS}

Paper plots may be made on large-format plotters such as HP650C, HP755C, and HP2500C directly from the included PostScript plot file.

\section{DATABASE CONTENTS}

The files constituting the geologic map database of this Open-File Report are listed below along with the interchange files from which they are extracted.

\section{Data Package}

All files listed below are in a compressed tar file named lkvw.tar.gz (2Mb); see section below titled, SOFTWARE UTILITIES.

\begin{tabular}{|c|c|c|}
\hline $\begin{array}{l}\text { ARC/INFO } \\
\text { interchange files }\end{array}$ & $\begin{array}{l}\text { Lakeview } \\
\text { coverages }\end{array}$ & $\underline{\text { Contains }}$ \\
\hline lkvw_geo.e00 & lkvw_geo & $\begin{array}{l}\text { Contacts, faults, and geologic units: geologic unit } \\
\text { labels as annotation subclass GEO, fault formal } \\
\text { names as annotation subclass FAULT }\end{array}$ \\
\hline lkvw_pts.e00 & lkvw_pts & $\begin{array}{l}\text { Structural point data: values in annotation } \\
\text { subclass }\end{array}$ \\
\hline lkvw_anno.e00 & lkvw_anno & Annotation leaders \\
\hline lines.rel.e00 & lines.rel & Line dictionary \\
\hline points.rel.e00 & points.rel & Point dictionary \\
\hline scamp2.shd.e00 & scamp2.shd & SCAMP shade set \\
\hline lakeview_summary.rel.e00 & lakeview_summary.rel & Coded geologic data; see Appendix I \\
\hline lakeview_lithology.rel.e00 & lakeview_lithology.rel & Coded geologic data; see Appendix I \\
\hline lakeview_structure.rel.e00 & lakeview_structure.rel & Coded geologic data; see Appendix I \\
\hline lakeview_genesis.rel.e00 & lakeview_genesis.rel & Coded geologic data; see Appendix I \\
\hline lakeview_protolith.e00 & lakeview_protolith.rel & Coded geologic data; see Appendix I \\
\hline
\end{tabular}

The directory, info/, is produced in the process of importing interchange files to ARC coverages and data files in ARC/INFO. The Lakeview info/ directory contains:

Feature Attribute tables

$\begin{array}{ll}\text { lkvw_geo.pat } & \text { Polygon attribute table } \\ \text { lkvw_geo.aat } & \text { Arc attribute table } \\ \text { lkvw_ldr.aat } & \\ \text { lkvw_pts.pat } & \text { Point attribute table } \\ \text { lkvw_anno.aat } & \text { Arc attribute table }\end{array}$


$\underline{\text { INFO data tables }}$

\author{
lakeview_summary.rel \\ lakeview_lithology.rel \\ lakeview_structure.rel \\ lakeview_genesis.rel \\ lakeview_protolith.rel \\ lines.rel \\ points.rel
}

Contains coded geologic data unique to Lakeview quadrangle Contains coded geologic data unique to Lakeview quadrangle Contains coded geologic data unique to Lakeview quadrangle Contains coded geologic data unique to Lakeview quadrangle Contains coded geologic data unique to Lakeview quadrangle Dictionary, contains all SCAMP line codes (Matti and others, 1998a) Dictionary, contains all SCAMP point codes(Matti and others, 1998b) $\underline{\text { Raster file }}$

lkvw.tif

$\underline{\text { ASCII text file }}$

poly_attrib_code.txt

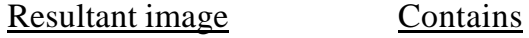

Lakeview basemap
Topographic base from 500 dpi scan of

USGS Lakeview 7.5’ quadrangle, 1967

Polygon attribute codes listed alphabetically and their explanations.

(Matti and others, 1998a)

\section{Plot Package}

PostScript plot file of the geologic map and CMU/DMU; please see section below titled, SOFTWARE UTILITIES for additional information.

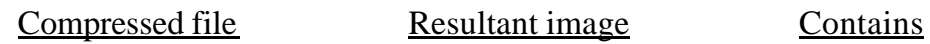

lkvw_map.ps.gz $\quad$ lkvw_map.ps $\quad$ PostScript plot file of geologic map and CMU/DMU

PostScript files are compressed and require gzip to uncompress them.

The uncompressed PostScript file lkvw_map.ps will plot a 1:24,000 scale, full color geologic map of the Lakeview quadrangle on a topographic base. A detailed CMU diagram, a DMU, and a regional structure map are included on the sheet. This sheet is in the editorial format of the U.S. Geological Survey's Miscellaneous Investigations (I) map series, and is approximately 45 X 32 inches in size. The map sheet has been successfully plotted on Hewlett-Packard large-format plotters, models HP650C, HP755CM, and HP2500C.

\section{Other files}

\author{
Readme.pdf \\ lkvw_map.pdf \\ poly_attrib_code.pdf
}

This document in .pdf format

Geologic map, DMU, and CMU

Alphabetical listing of polygon codes and code explanations

\section{SOFTWARE UTILITIES}

Files which have .gz file extension were compressed using gzip. Gzip utilities are available free of charge via the internet at the gzip home page, http://www.gzip.org

The data package is additionally bundled into a single tar (tape archive) file. Individual files must be extracted using a tar utility, available free of charge via the Internet through links on the Common Internet File Formats page, http://www.matisse.net/files/formats.html. One such utility is WinZip, available at http://www.winzip.com (WinZip can also decompress files). 
Files in the plot package have been prepared to produce optimum plots using the shade, and marker sets listed below.

The marker, line and shade (pattern) sets may be obtained at the web site

http://wrgis.wr.usgs.gov/docs/ncgm/scamp/scamp.html.

Geoage font group may be obtained at the following web site

Server: onyx.wr.usgs.gov

UserID: anonymous

Password:Your e-mail address

Directory: pub/wpg/supplies/geoage

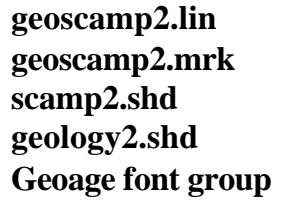

\author{
Lines \\ Points \\ Colors (included in data package) \\ Patterns \\ Geologic Age Symbols
}

\section{HOW TO OBTAIN THE DIGITAL FILES}

The export files, and subsequently the data and plot files, constituting the geologic map database of this Open-File Map may be obtained in two ways, both over the Internet.

1. Via the Web from Western Region Geologic Information Server. Go to the web page at http://geopubs.wr.usgs.gov/open-file/of01-174 and follow the directions to download the files.

2. By anonymous ftp over the Internet from wrgis.wr.usgs.gov. The files are located in the directory /pub/open-file/of01-174. Be sure to use binary transfer mode or ASCII mode for individual .e00 files (ARC interchange file format).

\section{HOW TO EXTRACT THE GEOLOGIC MAP DATABASE FROM THE TAR FILE}

After downloading the files, they must be uncompressed using a gzip utility such as gzip itself, Stuff It Expander or WinZip. The data files must then be extracted using a tar utility.

This process will create a directory, lkvw/, that contains the ARC/INFO interchange files and supporting files. The directory should contain the following files:

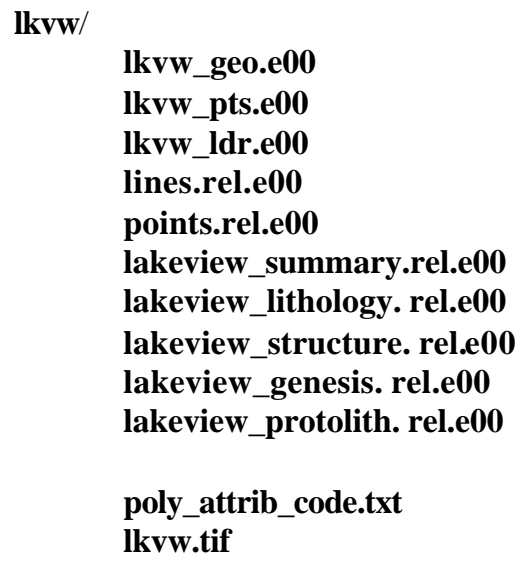

The following are not included in the database tar file, and are downloaded separately

lkvw_map.ps.gz

poly_attrib_code.pdf 


\section{Readme.pdf}

lkvw_map.pdf

\section{PostScript plot files}

Make a 16 MB uncompressed file, lkvw_map.ps (plot of complete map), by typing gzip -d lkvw_map.ps.gz (or use gzip utility of choice) and/or

\section{Portable Document Format (.pdf) files}

PDF files are not stored as gzip files. They are accessed using Adobe Acrobat Reader software, available free from the Adobe website http://www.adobe.com Follow instructions at the website to download and install the software. Acrobat Reader contains an on-line manual and tutorial.

\section{HOW TO CONVERT THE ARC/INFO INTERCHANGE (EXPORT) FILES}

The ARC interchange (.e00) files are converted to ARC coverages using the ARC command IMPORT.

ARC interchange files can also be read by some other Geographic Information Systems, including Arc View (ESRI) and MapInfo (http://www.mapinfo.com) (Environmental Systems Research Institute, Inc, 1991). Please consult your GIS documentation to see if you can use ARC interchange files and the procedure to import them.

\section{DIGITAL GEOLOGIC MAP SPECIFICATIONS}

\section{Digital and geologic compilation of geologic map}

The geologic map information was hand digitized from a base-stable original (ink on a greenline) of the geologic map at 1:24,000 scale. Digital tics were placed by hand at latitude/longitude intersections. The lines, points, and polygons were edited using standard ARC/INFO commands, and in some places, interactively by hand using graphical user interface ALACARTE (Fitzgibbon, 1991, Fitzgibbon and Wentworth, 1991, Wentworth and Fitzgibbon, 1991). Digitizing and editing artifacts significant enough to display at a scale of 1:24,000 were corrected.

\section{Base map}

The base map image (lkvw.tif, Geotiff format) was prepared by scanning a scale-stable clear film of the U.S Geological Survey, 1:24,000 Lakeview 7. 5' quadrangle (1967) topographic map. Scanning was done using an Anatech Eagle 4080 monochrome 800 dpi scanner at a resolution of 500 dpi. The raster scan was converted to a monochromatic image in ARC/INFO, and registered and rectified to the Lakeview 7.5' quadrangle. No elements of the base layer are attributed. The base map is provided for reference only.

\section{Spatial resolution}

Use of this digital geologic map database should not violate the spatial resolution of the data. Although the digital form of the data removes the constraint imposed by the scale of a paper map, the detail and accuracy inherent in map scale are also present in the digital data. The fact that this database was edited at a scale of 1:24,000 means that higher resolution information is not generally present in the dataset. Plotting at scales larger than 1:24,000 will not yield greater real detail, although it may reveal fine-scale irregularities above the intended resolution of the database. Similarly, although higher resolution data is incorporated at some places, the resolution of the combined output will be limited by the lower resolution data.

\section{Map accuracy standards}

Until uniform National geologic map accuracy standards are developed and adopted, lines and points on SCAMP 1:24,000 scale geologic maps that are located to within 15 meters, relative to accurately located features on the base map, are considered to meet map accuracy standards. Dashed lines, indicated in the database coding as not 
meeting map accuracy standards, are generally located to within 30 meters, relative to accurately located features on the base map.

\section{Database specifics}

General-The map database consists of ARC/INFO format coverages which are stored in polyconic projection (Table 1), and a series of data tables. Digital tics define a 7.5-minute grid of latitude and longitude in the geologic coverages corresponding to the 7.5-minute tic grid on the topographic base map.

\begin{tabular}{|c|c|}
\hline Projection & Polyconic \\
\hline Datum & NAD27 \\
\hline Zunits & No \\
\hline Units & Meters \\
\hline Spheroid & Clark 1866 \\
\hline$X$ shift & 0.0000000000 \\
\hline Y shift & 0.0000000000 \\
\hline Parameters & -117345.000 longitude of central meridian \\
\hline \multicolumn{2}{|c|}{334500 latitude of projection's origin } \\
\hline \multicolumn{2}{|c|}{0.00000 false easting (meters) } \\
\hline \multicolumn{2}{|c|}{0.00000 false northing (meters) } \\
\hline
\end{tabular}

The content of the geologic database can be described in terms of feature classes that include lines, points, and areas that comprise the map. See the metadata text file (Appendix I) for detailed descriptions.

Lines - Lines are recorded as strings of arcs and are described in an arc attribute (.aat) table in Appendix I. They represent contacts and faults which define the boundaries of map units and map boundaries.

Polygons-Geologic map units (polygons) are described in the polygon attribute table in Appendix I. In addition, using a system developed under the Southern California Areal Mapping Project (SCAMP), the Lakeview quadrangle is encoded with detailed, polygon-specific geologic information on a polygon-by-polygon basis, so that within the quadrangle, lateral variations in a particular map unit can be recorded in the map database. For traditional descriptions of the map units, see the Portable Document Format file lkvw_map.pdf. A list of all map units in the database is given in Appendix I.

Points - Point information (attitudes of planar and linear features, and line ornamentation) is recorded as coordinate and related information and is given in Appendix I.

Overview of data table (.rel) contents - In each data table the items TAG (polygons), L-TAG (lines), and P-TAG (points) are the common items enabling users to establish relate environments that provide flexibility and access to as much or as little of the encoded, detailed geologic data as required (A complete description of the line, point, and polygont data coding schemes is available in Matti and others, 1998a, b, and c).

$\underline{\text { Data Table }}$

lakeview_summary.rel

lakeview_lithology.rel

lakeview_structure.rel

lakeview_genesis. rel

lakeview_protolith. rel

\section{$\underline{\text { Attribute Data }}$}

- contains general, geologic information about age, rock type, rock-unit classification, and origin - contains lithologic attributes for each of five major rock types that occur within a geologic-map rock unit - contains geologic-structure attributes for each of the major rock types -contains summary attribute data describing the genesis of each of the major rock types -contains protolith attribute data for each of the major rock types that applies to both metamorphic and strain- 
dominated rocks

lines.rel

-line dictionary that contains a full description of each line type

points.rel

-point dictionary that contains a full description of each point type

Coded detailed geologic data-Up to ten data files, consisting of one selected data file and nine related data files can be temporarily joined using the RELATE command. The following is an example of how to establish a simple relate environment and the ARC/INFO dialogue the user will encounter.

At the Arc prompt, type: relate add

Dialogue for ADD

Relation name: name of relate you want to establish

Table identifier: pathname or database table name of the data file

Database name: name of the database in which the data file is stored

Info item: the item name in an INFO data file from which the relate is performed

Relate column: the field in the related table which is related to the INFO item

Relate type:

the type of relate performed-one of the following four: LINEAR,

ORDERED, LINK, TABLE. LINEAR is the slowest, but the simplest to

apply. (Please consult ARC/INFO online help topic such as "working

with tables' for help on selection of relate type)

Relate access: the access rights to the related file: RW, or RO, or AUTO

The table below shows an example using files from the Lakeview database.

Arc: relate add

Relation name: carbonate

Table identifier: lakeview_lithology.rel

Database name: info

INFO item: tag

Relate column: tag

Relate type: linear

Relate access: rw

To save a particular relate environment:

Arc: relate save <name of relate>

To restore a particular relate environment:

Arc: relate restore <name of relate>

To use the relate environment in the selection process:

select <relate name $>/ /<$ item $>$ cn '.search target.'

An example using Lakeview data:

Ae: select carbonate//lith2 cn '.SEDLC.'

Only the polygon data structure is described below, but the line and point data have similar structure. Coding is accomplished through the use of alpha-numeric characters separated by parsing symbols, dots (.) that separate primary attribute data, and hyphens (-) that separate secondary attribute data. The data base is structured to mimic geologists' methods of describing geologic units and their attributes, that is, beginning with general observations 
and expanding to progressively more specific details. To parallel this process, the polygon-attribute data base is organized into the following topics:

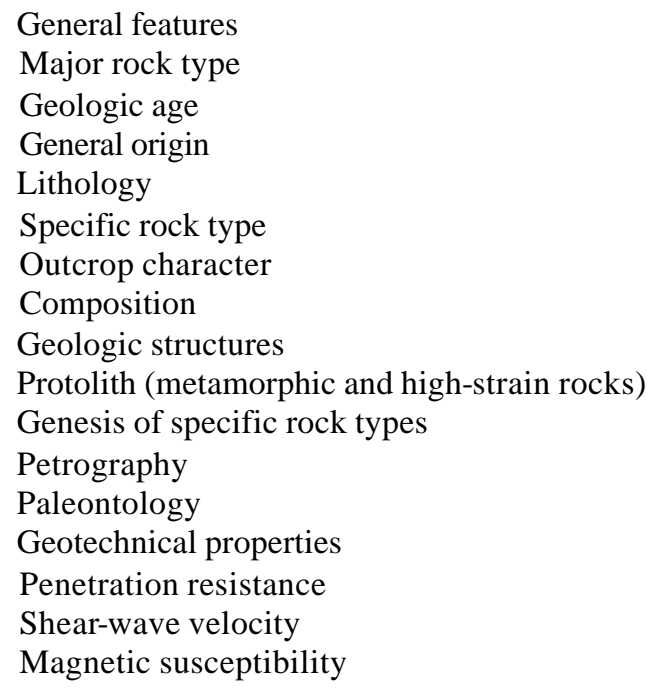

Typically, geologic descriptions are a series of phrases linking various attributes of a map unit. The following example of a unit description and the corresponding coding might best illustrate how the SCAMP encoding system is organized and utilized:

\section{Description: Mill Creek Formation (Miocene)}

Main rock-type of Mill Creek Formation is quartzofeldspathic sandstone that is ledgeforming, very pale brown to pale yellow, medium to thick-bedded, well cemented, poorly sorted, pebbly, fine to very coarse sand-size, flat-laminated to ripple-laminated, with rounded pebbles of basalt. Secondary rock type interlayered with main rock type consists of mudrock that is clay-rich, slope-forming, grayish green to brown, laminated to indistinctly bedded, consolidated to indurated, texturally massive to flat-laminated, mud-cracked locally, having calcareous concretions and trace fossils.

In addition to these two lithologic types, the Mill Creek Formation is also:

locally broken by numerous small faults, and all occurrences of the map unit are laced by networks of randomly-oriented fractures, most open but some partially closed with zeolitic cement.

Coding for this unit, given below, reflects the lithologic complexity, and allows search-and-retrieval analysis which targets geologic categories that are as broad or as narrow as the map-user requires. This coding scheme emphasizes relations among related geologic attributes, but also allows clear separation among non-related attributes. The following coding also illustrates how specific data are arranged in INFO data tables.

\section{Coding: Mill Creek Formation (Miocene)}

$\underline{\text { Data table }} \quad \underline{\text { Item }} \quad \underline{\text { Code }} \quad \underline{\text { Code explanations from Polygon-Attribute Code List }}$

Summary.rel

$\begin{array}{ll}\text { TAG } & \text { TmcA } \\ \text { AGE } & \text {.CZOTM.LMAC. } \\ \text { AGECON } & \text {.FSLC. } \\ \text { TYPE } & \text {.BRK.SED.SEDS } \\ \text { CLASS } & \text {.RSCBFF. } \\ & \\ \text { ORIGIN } & \text {.BRDS. }\end{array}$

Unit identifier

.Cenozoic, Miocene.Clarendonian. .age based on fossils, age certain. .bedrock.sedimentary.sedimentary, siliclastic. .classification of map unit, bedrock, formal, formation rank. braided, sand-bed. 
Lithology.rel

$\begin{array}{lll}\text { TAG } & \text { TmcA } & \text { Unit identifier } \\ \text { LITH1 } & \text {.GRK.GRKSSCP. } & \text {.grainrock.sandstone, pebbly.quartzofeldspathic. } \\ & \text { QFD.OGML.COLBPV. } & \text { ledge-forming.brown, pale, very.yellow,pale.bedding, } \\ & \text { COLYP.BEDMK.INDE. } & \text { medium to thick.indurated.poorly sorted.grainsize, } \\ & \text { GSOP.GSZSVFVC. } & \text { sand, fine to very coarse.lamination, flat.lamination, } \\ & \text { SDSLF.SDSLR.CCOIVB. } & \text { ripple.clast composition, basalt } \\ \text { LITH2 } & \text {.MRK.MRKM.OGMS. } & \text {.mudrock.mudstone.slope-forming.gray, greenish. } \\ & \text { COLGE.COLBG.BEDL. } & \text { brown, grayish.bedding, laminated.bedding, } \\ & \text { BEDI.INDCI.SDSMFL. } & \text { indistinct.consolidated to indurated.massive to } \\ & \text { SDSMK. } & \text { flat laminated.mud cracks. }\end{array}$

Structure.rel

$\begin{array}{ll}\text { TAG } & \text { TmcA } \\ \text { LITH1 } & \text {.SDFNFL.SDFNRO. } \\ & \text { SDFNRCP-FRAR- } \\ \text { LITH2 } & \text {.SDFNFL.SDFNRO. } \\ & \text { SDFNRCP-FRAR- }\end{array}$

Unit identifier

.faults, local small.fractures, open.fractures, partly closed-fractures random-

.faults, local small.fractures, open.fractures, partly closed-fractures random-

Genesis.rel

$\begin{array}{ll}\text { TAG } & \text { TmcA } \\ \text { LITH1 } & \text {.NMA.ALP.FLUV. } \\ & \text { BRDS. } \\ \text { LITH2 } & \text {.DELPL.MNDF. }\end{array}$

Unit identifier .nonmarine.alluvial-plain.alluvial valley setting. braided sand-bed.

.delta-plain deposits.fine-grained, meandering.

Paleontology.rel
TAG
TmcA
Unit identifier
LITH1 .FOSN.FOSNP.FOSNT. .nonmarine fossils.nonmarine plants.trace fossils.

Searching the database- The digital data base of the Lakeview quadrangle can be searched in a number of wayseach requiring a basic understanding of both the database structure and ARC/INFO's logical expression syntax in order to take full advantage of ARC/INFO's selection tools. ARC/INFO has a number of selection commands that require the user to construct simple, logical expressions.

For example: $\quad$ Area GT 1000

<operand1> <logical operation><operand2>

Using a selection command (select) the user would be asking for areas greater than $1000 \mathrm{~m}^{2}$

$\underline{\mathrm{ARC} / \mathrm{INFO} \text { selection commands }}$

SELECT Selects features or data items

ASELECT Adds to your selected set of items or features

UNSELECT Removes selected features from your group of selected items.

RESELECT Selects a subset of items our of your group of selected items.

NSELECT Unselects all of your currently selected items and selects all those you did not have selected.

All of the selection commands except for NSELECT can be used in conjunction with logical expressions of operators and connectors so that you can select for or against any item that is coded in the database. The table below illustrates 
some ways to search the polygon data base. The examples use code sentences from two different polygon types (Item 1 and Item 2), using the data-base fields LABL and LITH1 (in LITHOLOGY.rel):

$\underline{\text { Item } 1} \underline{\text { Item } 2}$

LABL: $\quad$ Qal $\quad$ Qyf

LITH1: $\quad$.SDE.ESE.TES.TES.ZXE.SEES.MESE. $\quad$.SDE.ESE.TES.TES.ZXE.SEEB.MEII.

For Items 1 and 2 the two code sentences clearly are related, but they differ slightly in their last two codes.

$\underline{\text { OperatorExample expression Explanation }}$

CN Select LITH1 cn '.SEES.' This is a whole word search which would select sentence one above

$\mathrm{CN}$ Select LITH1 $\mathrm{cn}$ '.SEE' This is a prefix search that will select all items containing a code stringword with the prefix SEE. In this case both sentence one and two would be selected

CN Select LITH1 cn '.SEES.' This example uses a logical connector, AND, which and LABL cn 'Qal' would select all items that contain SEES and also are of type Qal. In this case, sentence one would be selected

The user can substitute any logical operator or logical connector to search and select for and/or against any combination of items coded in the database. Some of the operators and connectors that are useful include:

\section{Operators:}

CN Contains

NC Not containing

\section{Connectors:}

AND Only items for which the expressions on both side of the AND are true will be selected

OR Items for which the expressions on either side of the OR will be selected

XOR Items for which ONLY one of the expressions on either side of the XOR are true will be selected

Query and search of version 1.0 of the Lakeview database will provide the user with CODED output which will require reference to the alphabetical list of polygon attribute codes and their respective explanations

contained in the ASCII text file (poly_attrib_code.txt) included in the database package, lkvw.tar.gz. or in the pdf file poly_attrib_code.pdf. 


\title{
REFERENCES
}

Environmental Systems Research Institute, Inc, 1991, ARC/INFO command references 6.0: Proprietary software manual

Matti, J.C., Powell, R.E., Miller, F.K., Kennedy, S.A., Ruppert, K.R., Morton, G.L., and Cossette, P.M., 1998a, Geologic-line attributes for digital geologic map databases produced by the Southern California Areal Mapping Project (SCAMP), Version 1.0: U.S.Geological Survey Open-File Report 97-861

Matti, J.C., Miller, F.K., Powell, R.E., Kennedy, S.A., Bunyapanasarn, T.P., Koukladas, Catherine, Hauser, R.M., and Cossette, P.M., 1998b, Geologic-point attributes for digital geologic map databases produced by the Southern California Areal Mapping Project (SCAMP), Version 1.0: U.S.Geological Survey Open-File Report 97-859

Matti, J.C., Miller, F.K.,Powell, R.E., Kennedy, S.A., and Cossette, P.M., 1998c, Geologic-polygon attributes for digital geologic-map databases produced by the Southern California Areal Mapping Project (SCAMP), Version 1.0: U.S.Geological Survey Open-File Report 97-860

\author{
$\underline{\text { APPENDIX I }}$ \\ Identification_Information: \\ Citation: \\ Citation_Information: \\ Originator: D.M. Morton \\ Originator: J.C. Matti \\ Publication_Date: 2001 \\ Title: Geologic map of the Lakeview 7.5' quadrangle, Riverside County, California \\ Edition: Version 1.0 \\ Geospatial_Data_Presentation_Form: vector digital data \\ Series_Information: \\ Series_Name: U.S. Geological Survey Open-File Report \\ Issue_Identification: USGS OF 01-174 \\ Publication_Information: \\ Publication_Place: Menlo Park, California \\ Publisher: U.S. Geological Survey \\ Online_Linkage: http://geopubs.wr.usgs.gov/open-file/of01-174 \\ Description:
}

\begin{abstract}
:
This data set maps and describes the geology of the Lakeview 7.5' quadrangle, Riverside County, California. The quadrangle encompasses part of the northern Peninsular Ranges Province. Tonalitic granitic rocks of the Cretaceous Peninsular Range batholith dominate the bedrock areas, and include rocks ranging in composition from monzogranite to gabbro. The Lakeview Mountains are underlain chiefly by tonalite of the Lakeview pluton and related rocks. In the northeastern corner of the quadrangle, Tertiary sedimentary rocks of the San Timoteo beds of Frick (1921) and Mount Eden Formation of Fraser (1931) rest on Paleozoic schist, quartzite, gneiss, and marble having a well developed east dipping foliation. The Tertiary formations are much more extensively exposed in the San Timoteo Badlands to the northeast and southeast. These Tertiary and Paleozoic units are separated from the Lakeview Mountains by the San Jacinto Valley, which locally contains up to 3,000 m of Quaternary sediments. Two strands of the seismically active San Jacinto Fault zone bound the Valley, the Claremont Fault on the northeast side, and the Casa Loma Fault on the southwest side. Numerous cracks and fissures
\end{abstract}


related to both groundwater withdrawal and tectonic movements are developed in the Quaternary sediments, especially in the northern part of the quadrangle.

Created using Environmental Systems Research Institute's ARC/INFO software, the database consists of the following items: (1) a map coverage containing faults, geologic contacts and units, (2) a coverage showing structural data, (3) a coverage containing geologic unit annotation and leaders, and (4) five additional INFO data tables (.rel) that contain detailed, coded, geologic information such as texture, fabric, color, and mineralogy and (5) line and point dictionaries, lines.rel and points.rel. These additional data are accessible to the user through the utilization of ARC/INFO relate environments and provide the user access to as much or as little of the encoded data as required. In addition, the data set includes the following graphic and text products: (1) A PostScript graphic plot-file containing the geologic map, topography, cultural data, a Correlation of Map Units (CMU) diagram, a Description of Map Units (DMU), and a key for point and line symbols, and (2) PDF files of this Readme (including the metadata file as an appendix), the poly_attrib_code.txt (the polygon attribute coding), and the graphic produced by the Postscript plot file.

The geologic map database contains original U.S. Geological Survey data generated by detailed field observation and by interpretation of aerial photographs. Within the database, geologic contacts are represented as lines (arcs), geologic units as polygons, and site-specific data as points. Polygon, arc, and point attribute tables (.pat, .aat, and .pat, respectively) uniquely identify each geologic datum.

Purpose:

The data set for the Lakeview quadrangle has been prepared by the Southern California Areal Mapping Project (SCAMP), a cooperative project sponsored jointly by the U.S. Geological Survey and the California Division of Mines and Geology. The Lakeview data set represents part of an ongoing effort to create a regional GIS geologic database for southern California. This regional digital database, in turn, is being developed as a contribution to the National Geologic Map Database of the National Cooperative Geologic Mapping Program of the USGS.

The digital geologic map database for the Lakeview 7.5' quadrangle has been created as a general-purpose data set that is applicable to other land-related investigations in the earth and biological sciences. For example, it can be used for groundwater studies in the San Bernardino basin, and for mineral resource evaluation studies, animal and plant habitat studies, and soil studies in the San Bernardino National Forest. The database is not suitable for site-specific geologic evaluations.

Supplemental_Information:

Within the geologic map database, map units are identified by standard geologic map criteria such as formation-name, age, and lithology. The authors have attempted to adhere to the stratigraphic nomenclature of the U.S. Geological Survey and the North American Stratigraphic Code, but the database has not received a formal editorial review of geologic names.

Geologic map unit labels entered in database items LABL and PLABL contain substitute characters for conventional stratigraphic age symbols: Paleozoic appears as 'Pz' in LABL and as '|' in

PLABL. The substitute characters in PLABL invoke their corresponding symbols from the GeoAge font group to generate map unit labels with conventional stratigraphic symbols.

Time_Period_of_Content:

Time_Period_Information:

Range_of_Dates/Times:

Beginning_Date: 19620401

Ending_Date: 20000201

Currentness_Reference: New data

Status:

Progress: Complete

Maintenance_and_Update_Frequency: As needed 
Spatial_Domain:

Bounding_Coordinates:

West_Bounding_Coordinate: -117.12509085

East_Bounding_Coordinate: -116.99990904

North_Bounding_Coordinate: 33.87499933

South_Bounding_Coordinate: 33.74998308

Keywords:

Theme:

Theme_Keyword_Thesaurus: None

Theme_Keyword: geologic map

Theme_Keyword: geology

Theme_Keyword: bedrock geology

Theme_Keyword: Active fault

Theme_Keyword: San Jacinto Fault

Theme_Keyword: surficial geology

Place:

Place_Keyword_Thesaurus: None

Place_Keyword: California

Place_Keyword: Riverside County

Place_Keyword: Lakeview 7.5' quadrangle

Place_Keyword: Peninsular Ranges

Stratum:

Stratum_Keyword_Thesaurus: None

Stratum_Keyword: Peninsular Ranges batholith

Stratum_Keyword: Granitic rocks

Stratum_Keyword: Tonalite

Access_Constraints: None

Use_Constraints:

The Lakeview 7.5' geologic-map database should be used to evaluate and understand the geologic character of the Lakeview 7.5' quadrangle as a whole. The data should not be used for purposes of site-specific land-use planning or site-specific geologic evaluations. The database is sufficiently detailed to identify and characterize geologic materials and structures. However, it is not sufficiently detailed for site-specific determinations.

Use of this digital geologic map database should not violate the spatial resolution of the data. Although the digital form of the data removes the constraint imposed by the scale of a paper map, the detail and accuracy inherent in map scale are also present in the digital data. The fact that this database was compiled and edited at a scale of 1:24,000 means that higher resolution information may not have been uniformly retained in the dataset. Plotting at scales larger than 1:24,000 will not yield greater real detail, although it may reveal fine-scale irregularities below the intended resolution of the database. Similarly, although higher resolution data is incorporated in parts of the map, the resolution of the combined output will be limited by the lower resolution data.

\author{
Point_of_Contact: \\ Contact_Information: \\ Contact_Person_Primary: \\ Contact_Person: D.M. Morton \\ Contact_Organization: U.S. Geological Survey, Western Region, Earth Surface Processes Team \\ Contact_Position: Project chief \\ Contact_Address:
}


Address_Type: mailing address

Address:

U.S. Geological Survey

Department of Geology

University of California, Riverside

City: Riverside

State_or_Province: California

Postal_Code: 92521

Country: United States of America

Contact_Voice_Telephone: (909) 276-6397

Contact_Facsimile_Telephone: (909) 276-6295

Contact_Electronic_Mail_Address: scamp@usgs.gov

Browse_Graphic:

Browse_Graphic_File_Name: http://geopubs.wr.usgs.gov/open-file/of01-174/images/lkvw_browse.jpg

Browse_Graphic_File_Description:

Non-navigable .jpg image of the geologic map, topographic base, Correlation of Map Units,

Description of Map Units and key to point and line symbols

Browse_Graphic_File_Type: .jpg

Browse_Graphic:

Browse_Graphic_File_Name: http://geopubs.wr.usgs.gov/open-file/of01-174/images/lkvw_map.pdf

Browse_Graphic_File_Description:

Navigable portable document file (.pdf) image of the geologic map, topographic base,

Correlation of Map Units, Description of Map Units and key to point and line symbols.

Browse_Graphic_File_Type:.pdf

Data_Set_Credit:

Technical review by M. Dawson and F. Miller led to significant improvements that eventually were reflected in aspects of the database, the plot file, and in the description of the geologic units of the Lakeview 7.5' quadrangle. Digital review by R.W. Graymer has allowed us to prepare a much improved product.

Geologic mapping and digital preparation of this report were sponsored jointly by (1) the National Cooperative Geologic Mapping Program of the U.S. Geological Survey, (2) the California Division of Mines and Geology, and (3) the Southern California Areal Mapping Project (SCAMP). The digital preparation of the data set was carried out by Rachel Alvarez and Gary Patt at the SCAMP Geographic Information System laboratory in Riverside, and by Pamela M. Cossette at the USGS Mineral Resources Program GIS lab in Spokane, Washington.

Native_Data_Set_Environment: SunOS, 5.6, sun4u UNIX ARC/INFO version 7.2.1

Cross_Reference:

Citation_Information:

Originator: D.M. Morton

Publication_Date: 1972

Title: Geology of the Lakeview-Perris quadrangles, Riverside County, California

Geospatial_Data_Presentation_Form: paper map

Series_Information:

Series_Name: California Division of Mines and Geology Map Sheet

Issue_Identification: Map Sheet 19

Publication_Information:

Publication_Place: Sacramento, California

Publisher: California Division of Mines and Geology

Data_Quality_Information:

Attribute_Accuracy: 
Attribute_Accuracy_Report:

Geologic-map units in the Lakeview quadrangle database were described using standard field methods. Consistent with these methods, the database author has assigned standard geologic attributes to geologic lines, points, and polygons identified in the database.

Nation-wide geologic-map accuracy standards have not been developed and adopted by the U.S. Geological Survey and other earth-science entities. Until such standards are adopted, the

SCAMP project has developed internal map-accuracy standards for 1:24,000-scale geologic maps produced by the project.

Geologic lines and points on 1:24,000 scale geologic maps are judged to meet SCAMP's internal map-accuracy standards if they are located to within 15 meters, relative to topographic or cultural features on the base map.

Lines and points that meet (or may not meet) this SCAMP internal map-accuracy standard are identified both in the digital database and on derivative geologic-map plots. Within the database, line and point data that are judged to meet the SCAMP internal map-accuracy standard are denoted by the attribute code .MEE. (meets) in the appropriate data table; line and point data that may not meet the SCAMP internal map-accuracy standard are denoted by the attribute code .MNM. (may not meet).

On any derivative geologic-map plot, line data that are judged to meet the SCAMP internal map-accuracy standard are denoted by solid lines; line data that may not meet the SCAMP internal map-accuracy standard are denoted by dashed or dotted lines. There is no cartographic device for denoting the map-accuracy for geologic-point data (eg. symbols representing bedding, foliation, lineations, etc.).

Logical_Consistency_Report:

Polygon and chain-node topology present.

The areal extent of the map is represented digitally by an appropriately projected (Polyconic projection), mathematically generated box. Consequently, polygons intersecting the lines that comprise the map boundary are closed by that boundary. Polygons internal to the map boundary are completely enclosed by line segments which are themselves a set of sequentially numbered coordinate pairs. Point data are represented by coordinate pairs.

\section{Completeness_Report:}

The geologic map and digital database of the Lakeview 7.5' quadrangle contain new data that have been subjected to rigorous review and are a substantially complete representation of the current state of knowledge concerning the geology of the quadrangle.

Positional_Accuracy:

Horizontal_Positional_Accuracy:

Horizontal_Positional_Accuracy_Report:

The maximum transformation RMS error acceptable for 7.5' quadrangle transformation and data input is 0.003 (7.6 meters). Horizontal positional accuracy was checked by visual comparison of hard-copy plots with base-stable source data.

Lineage:

Process_Step:

Process_Description:

Field mapping and aerial photograph interpretation; iterative process (D.M. Morton and J.C. Matti). 
Process_Date: 1962-1963 and 1980

Process_Step:

Process_Description:

Transfer of geologic linework and point data from field maps and aerial photographs to a

scale-stable cartographic base of quadrangle (scribeguide) (D.M. Morton and J.C. Matti).

Process_Date: 1964 and 1981

Process_Step:

Process_Description: Description of Map Units and Correlation of Map Units (D.M. Morton and J.C. Matti)

Process_Date: 1964, 1981, and 1998

Process_Step:

Process_Description:

The geologic map information was hand digitized from author-prepared base-stable geologic map at 1:24,000 scale. (Rachel Alvarez and Gary Patt). Preliminary ARC/INFO database established.

Process_Date: 1994

Process_Step:

Process_Description:

Detailed ARC/INFO database established; cleanup of ditizing artifacts; polygon, arc, and point attribute tables established using model developed for SCAMP coverages. Digitizing and editing artifacts significant enough to display at a scale of 1:24,000 were corrected (P.M. Cossette).

Process_Date: 1999

Process_Step:

Process_Description:

Polygons coded with detailed geologic information using model developed for SCAMP coverages.

(D.M. Morton and F.K. Miller).

Process_Date: 1999

Process_Step:

Process_Description:

First draft of metadata created by cossette using FGDCMETA.AML ver. 1.2 05/14/98 on ARC/INFO

data set /pool5/c/cossette2/lakeview/lkv-nonof/lkvw_geo

Process_Date: 20010320

Spatial_Data_Organization_Information:

Direct_Spatial_Reference_Method:Vector

Point_and_Vector_Object_Information:

SDTS_Terms_Description:

SDTS_Point_and_Vector_Object_Type: Point

Point_and_Vector_Object_Count: 378

SDTS_Point_and_Vector_Object_Type: String

Point_and_Vector_Object_Count: 1083

SDTS_Point_and_Vector_Object_Type: GT-polygon composed of chains

Point_and_Vector_Object_Count: 379

Spatial_Reference_Information:

Horizontal_Coordinate_System_Definition:

Planar:

Map_Projection:

Map_Projection_Name: Polyconic

Polyconic:

Latitude_of_True_Scale: $\quad 33.75$

Longitude_of_Central_Meridian: -117.0625

Latitude_of_Projection_Origin: 33.7500

False_Easting: 0.00000

False_Northing: 0.00000

Planar_Coordinate_Information: 
Planar_Coordinate_Encoding_Method: coordinate pair

Coordinate_Representation:

Abscissa_Resolution: 0.000001

Ordinate_Resolution: 0.000001

Planar_Distance_Units: Meters

Geodetic_Model:

Horizontal_Datum_Name: North American Datum of 1927

Ellipsoid_Name: Clarke 1866

Semi-major_Axis: 6378206.4

Denominator_of_Flattening_Ratio: 294.98

Entity_and_Attribute_Information:

Overview_Description:

Entity_and_Attribute_Overview:

Version 1.0 of the Lakeview 7.5' quadrangle comprises three ARC/INFO coverages, of which two

contain geologic data and one contains cartographic features: lkvw_geo (geology), lkvw_pts

(structural point data), and lkvw_anno (geologic unit annotation and leaders). Geospatial

entities in ARC/INFO coverages have the following software-defined attributes: <cover>.pat

contains AREA, PERIMETER, cover\#, and cover-ID; <cover> aat contains FNODE\#, TNODE\#, LPOLY\#,

RPOLY\#, LENGTH, cover\#, and cover-ID. User-defined attributes are described in detail

below.Two INFO tables, lines.rel and points.rel provide a full description of each of the geologic line and point features in the database. Full source citations are provided in the Entity_and Attribute_Detail_Citation section of this metadata document.

1) The coverage lkvw_geo includes a polygon feature attribute table (lkvw_geo.pat) that describes the geospatial distribution of rock units represented in the Postscript (.ps) and Portable Document Format (.pdf) plotfiles of the geologic maps and an arc feature attribute table (lkvw_geo.aat) that describes the contacts and faults that bound rock-unit polygons. Line and point identity data are recorded in the .aat and pat using a system of identity codes. Two INFO tables, lines.rel and points.rel, provide a full description of each of the geological line and point codes in the database. For display purposes in the .ps and .pdf geologic maps, the geology coverage includes one annotation subclass: anno.fault, which contains formal fault names. In addition, the item TAG allows the user to access (relate to) a series of INFO data tables that contain additional, detailed, coded geologic data. A complete description of the polygon, line, and point data coding schemes is available in U.S. Geological Survey Open-File Reports 97-859, OFR 97-860, and OFR 97-861 (full source citations follow).

Five INFO data tables are included in the Lakeview database: lakeview_genesis.rel provides data summarizing the genesis of each of the major rock types that occur within a particular map rock unit, lakeview_summary.rel provides general information about a rock unit,

lakeview_lithology.rel contains lithologic attributes for the main and secondary lithologic types in the geologic-map unit, lakeview_protolith.rel describes rock type protoliths, and lakeview_structure.rel contains geologic structural data. The tables have identical architecture. The item TAG serves as the relate item and there are five additional feature attribute items, LITH1...LITH5, that represent the major rock types within a rock unit. Lakeview_structure.rel contains an item STRHIST that contains attributes that describe the structural history of a particular unit.

2) The coverage lkvw_pts includes a point attribute table (lkvw_pts.pat) that describes both the types and orientation of bedding, foliation, and lineation. An annotation subclass displays the dip or plunge values associated with the point data.

3) The coverage lkvw_anno includes an arc attribute table (lkvw_ldr.pat) that describes annotation leaders and one annotation subclass, anno.geo, which contains unit labels derived from PLABL. Unit symbols that are placed outside the perimeter of a particular polygon 
identify that polygon with annotation leaders.

Entity_and_Attribute_Detail_Citation:

A complete description of the polygon, line, and point data coding schemes is available in the following U.S. Geological Survey Open-File Reports:

Matti, J.C., Miller, F.K., Powell, R.E., Kennedy, S.A., Bunyapanasarn, T.P., Koukladas, Catherine, Hauser, R.M., and Cossette, P.M., 1997b, Geologic-point attributes for digital geologic-map databases produced by the Southern California Areal Mapping Project (SCAMP), Version 1.0: U.S.Geological Survey Open-File Report 97-859

Matti, J.C., Miller, F.K., Powell, R.E., Kennedy, S.A., and Cossette, P.M., 1997c, Geologic-polygon attributes for digital geologic-map databases produced by the Southern California Areal Mapping Project (SCAMP), Version 1.0: U.S.Geological Survey Open-File Report 97-860

Matti, J.C., Powell, R.E., Miller, F.K., Kennedy, S.A., Ruppert, K.R., Morton, G.L., and Cossette, P.M., 1997a, Geologic-line attributes for digital geologic-map databases produced by the Southern California Areal Mapping Project (SCAMP), Version 1.0: U.S.Geological Survey Open-File Report 97-861

\author{
Detailed_Description: \\ Entity_Type: \\ Entity_Type_Label: LKVW_GEO.PAT \\ Entity_Type_Definition: Geologic map units \\ Attribute: \\ Attribute_Label: LABL \\ Attribute_Definition: \\ Geologic map unit label. Plain text is substituted for conventional geologic age symbols $(\mathrm{Pz}$ \\ for Paleozoic) and unit label subscripts as annotated on map \\ Attribute_Domain_Values: \\ Enumerated_Domain: \\ Enumerated_Domain_Value: Qw \\ Enumerated_Domain_Value_Definition: Very young wash deposits, arenaceous \\ Enumerated_Domain: \\ Enumerated_Domain_Value: Qyw \\ Enumerated_Domain_Value_Definition: Young wash deposits, arenaceous \\ Enumerated_Domain: \\ Enumerated_Domain_Value: Qf \\ Enumerated_Domain_Value_Definition: Very young alluvial-fan deposits, arenaceous \\ Enumerated_Domain: \\ Enumerated_Domain_Value: Qv \\ Enumerated_Domain_Value_Definition: Very young alluvial-valley deposits, siltey, clayey \\ Enumerated_Domain: \\ Enumerated_Domain_Value: Qc \\ Enumerated_Domain_Value_Definition: Very young colluvial deposits \\ Enumerated_Domain: \\ Enumerated_Domain_Value: Qlv \\ Enumerated_Domain_Value_Definition: Very young lacustrine and fluvial deposits, clayey, silty \\ Enumerated_Domain: \\ Enumerated_Domain_Value: Qyf \\ Enumerated_Domain_Value_Definition: Young alluvial-fan deposits, arenaceous \\ Enumerated_Domain: \\ Enumerated_Domain_Value: Qyf \\ Enumerated_Domain_Value_Definition: Young alluvial-fan deposits, gravel, arenaceous
}


Enumerated_Domain:

Enumerated_Domain_Value: Qyf6

Enumerated_Domain_Value_Definition: Young alluvial-fan deposits, Unit 6, gravel, arenaceous

Enumerated_Domain:

Enumerated_Domain_Value: Qyf5

Enumerated_Domain_Value_Definition: Young alluvial-fan deposits, Unit 5, gravel, arenaceous

Enumerated_Domain:

Enumerated_Domain_Value: Qyf4

Enumerated_Domain_Value_Definition: Young alluvial-fan deposits, Unit 4, gravel, arenaceous

Enumerated_Domain:

Enumerated_Domain_Value: Qyf3

Enumerated_Domain_Value_Definition: Young alluvial-fan deposits, Unit 3, gravel, arenaceous

Enumerated_Domain:

Enumerated_Domain_Value: Qyf2

Enumerated_Domain_Value_Definition: Young alluvial-fan deposits, Unit 2, gravel, arenaceous

Enumerated_Domain:

Enumerated_Domain_Value: Qyf1

Enumerated_Domain_Value_Definition: Young deposits of allu vial fans, Unit 1, gravel, arenaceous

Enumerated_Domain:

Enumerated_Domain_Value: Qya

Enumerated_Domain_Value_Definition: Young axial-valley floor deposits, arenaceous

Enumerated_Domain:

Enumerated_Domain_Value: Qyv

Enumerated_Domain_Value_Definition: Young alluvial-valley deposits, arenaceous

Enumerated_Domain:

Enumerated_Domain_Value: Qyv

Enumerated_Domain_Value_Definition: Young alluvial-valley deposits, clayey, arenaceous

Enumerated_Domain:

Enumerated_Domain_Value: Qyv

Enumerated_Domain_Value_Definition: Young alluvial-valley deposits, clayey, silty

Enumerated_Domain:

Enumerated_Domain_Value: Qyv

Enumerated_Domain_Va lue_Definition: Young alluvial-valley deposits, silty, arenaceous

Enumerated_Domain:

Enumerated_Domain_Value: Qyv

Enumerated_Domain_Value_Definition: Young alluvial-valley deposits, silty, clayey

Enumerated_Domain:

Enumerated_Domain_Value: Qyv1

Enumerated_Domain_Value_Definition: Young alluvial-valley deposits, Unit 1, arenaceous

Enumerated_Domain:

Enumerated_Domain_Value: Qyls

Enumerated_Domain_Value_Definition: Young landslide deposits

Enumerated_Domain:

Enumerated_Domain_Value: Qof

Enumerated_Domain_Value_Definition: Old alluvial-fan deposits, arenaceous

Enumerated_Domain:

Enumerated_Domain_Value: Qofv

Enumerated_Domain_Value_Definition: Old alluvial-fan deposits and very young alluvial-valley deposits, arenaceous

Enumerated_Domain:

Enumerated_Domain_Value: Qov

Enumerated_Domain_Value_Definition: Old alluvial-valley deposits

Enumerated_Domain:

Enumerated_Domain_Value: Qoc

Enumerated_Domain_Value_Definition: Old colluvial deposits

Enumerated_Domain: 
Enumerated_Domain_Value: Qoc

Enumerated_Domain_Value_Definition: Old colluvial deposits, gravel

Enumerated_Domain:

Enumerated_Domain_Value: Qvof

Enumerated_Domain_Value_Definition: Very old alluvial-fan deposits, arenaceous

Enumerated_Domain:

Enumerated_Domain_Value: Qvof

Enumerated_Domain_Value_Definition: Very old alluvial-fan deposits, gravel

Enumerated_Domain:

Enumerated_Domain_Value: Qvov

Enumerated_Domain_Value_Definition: Very old alluvial-valley deposits, arenaceous

Enumerated_Domain:

Enumerated_Domain_Value: Tstl

Enumerated_Domain_Value_Definition: San Timoteo beds of Frick (1921)

Enumerated_Domain:

Enumerated_Domain_Value: Tmeus

Enumerated_Domain_Value_Definition: Mount Eden Formation of Fraser (1931), upper sandstone member

Enumerated_Domain:

Enumerated_Domain_Value: Tmels

Enumerated_Domain_Value_Definition: Mount Eden Formation of Fraser (1931), lower sandstone member

Enumerated_Domain:

Enumerated_Domain_Value: Tmea

Enumerated_Domain_Value_Definition: Mount Eden Formation of Fraser (1931), arkosic sandstone member

Enumerated_Domain:

Enumerated_Domain_Value: Tmeb

Enumerated_Domain_Value_Definition: Mount Eden Formation of Fraser (1931), boulder breccia lenses

Enumerated_Domain:

Enumerated_Domain_Value: Tmec

Enumerated_Domain_Value_Definition: Mount Eden Formation of Fraser (1931), conglomeratic sandstone member

Enumerated_Domain:

Enumerated_Domain_Value: Kmeg

Enumerated_Domain_Value_Definition: Granite of Mount Eden

Enumerated_Domain:

Enumerated_Domain_Value: Klt

Enumerated_Domain_Value_Definition: Tonalite of Laborde Canyon

Enumerated_Domain:

Enumerated_Domain_Value: Ktcg

Enumerated_Domain_Value_Definition: Monzogranite of Tres Cerritos

Enumerated_Domain:

Enumerated_Domain_Value: Kp

Enumerated_Domain_Value_Definition: Lakeview Mountains pluton, pegmatite dikes

Enumerated_Domain:

Enumerated_Domain_Value: Klmt

Enumerated_Domain_Value_Definition: Lakeview Mountains pluton, tonalite

Enumerated_Domain:

Enumerated_Domain_Value: Klml

Enumerated_Domain_Value_Definition: Lakeview Mountains pluton, leucocratic tonalite

Enumerated_Domain:

Enumerated_Domain_Value: Klmm

Enumerated_Domain_Value_Definition: Lakeview Mountains pluton, melanocratic tonalite

Enumerated_Domain:

Enumerated_Domain_Value: Klmg

Enumerated_Domain_Value_Definition: Lakeview Mountains pluton, hypersthene-hornblende gabbro

Enumerated_Domain:

Enumerated_Domain_Value: Khg 


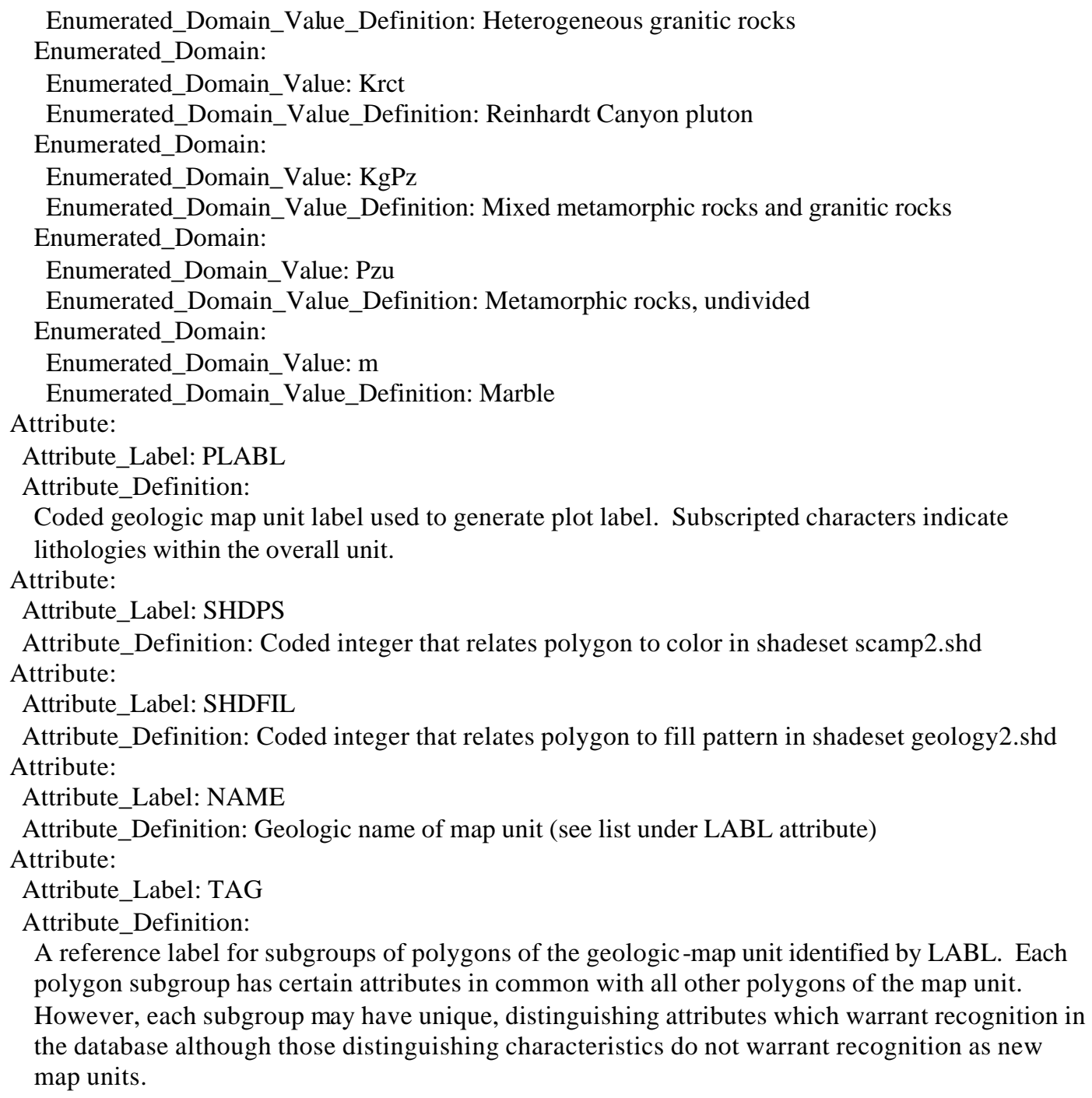

TAG is defined as LABL followed by an upper-case letter, e.g., QwA, QwB, or QwC, etc. Map units in the Lakeview quadrangle are assigned an A tag designation except for Qyv (QyvA, QyvB and QyvC) and Qyf (QyfA, QyfB and QyfC).

TAG serves one additional purpose: it functions as the relate item that associates each polygon with its attributes stored in the five polygon-attribute data tables identified in the Entity_and_Attribute_Overview section above.

Detailed_Description:

Entity_Type:

Entity_Type_Label: LKVW_GEO.AAT

Entity_Type_Definition: Geologic contacts and faults that bound rock-unit polygons

Attribute:

Attribute_Label: L-SYMB

Attribute_Definition: Coded integer symbol that relates arc to cartographic line symbol in lineset geoscamp2.lin

Attribute:

Attribute_Label: L-TAG

Attribute_Definition:

Coded alpha-numerical symbol that relates arc to definition of line type in dictionary

look-up table (lines.rel). For description of attributes in line classification

dictionary, refer to USGS Open-File Report 97-861 (see 
Entity_and_Attribute_Detail_Citation)

Attribute_Domain_Values:

Enumerated_Domain:

Enumerated_Domain_Value: C17

Enumerated_Domain_Value_Definition: Contact, landslide, location meets map accuracy standard

Enumerated_Domain:

Enumerated_Domain_Value: C29

Enumerated_Domain_Value_Definition: Contact, sedimentary, location meets map accuracy standard

Enumerated_Domain:

Enumerated_Domain_Value: C30

Enumerated_Domain_Value_Definition: Contact, sedimentary, location may not meet map accuracy standard

Enumerated_Domain:

Enumerated_Domain_Value: C31

Enumerated_Domain_Value_Definition: Contact, sedimentary, inferred, location may not meet map accuracy standard

Enumerated_Domain:

Enumerated_Domain_Value: C37 standard

Enumerated_Domain_Value_Definition: Contact, separates terraced alluvial units, location meets map accuracy

Enumerated_Domain:

Enumerated_Domain_Value: C41

Enumerated_Domain_Value_Definition: Contact, sedimentary, gradational, location may not meet map accuracy standard

Enumerated_Domain:

Enumerated_Domain_Value: C49

Enumerated_Domain_Value_Definition: Contact, igneous, location meets map accuracy standard

Enumerated_Domain:

Enumerated_Domain_Value: C50

Enumerated_Domain_Value_Definition: Contact, igneous, location may not meet map accuracy standard

Enumerated_Domain:

Enumerated_Domain_Value: C65

Enumerated_Domain_Value_Definition: Contact, metamorphic, location meets map accuracy standard

Enumerated_Domain:

Enumerated_Domain_Value: CL1

Enumerated_Domain_Value_Definition: Cartographic line, map boundary

Enumerated_Domain:

Enumerated_Domain_Value: DK9

Enumerated_Domain_Value_Definition: Dike, location may not meet map accuracy standard

Enumerated_Domain:

Enumerated_Domain_Value: F6

Enumerated_Domain_Value_Definition: Fault, high-angle, oblique slip, location meets map accuracy standard

Enumerated_Domain:

Enumerated_Domain_Value: F12

Enumerated_Domain_Value_Definition: Fault, high-angle, oblique slip, location may not meet map accuracy standard

Enumerated_Domain:

Enumerated_Domain_Value: F18

Enumerated_Domain_Value_Definition: Fault, high-angle, oblique slip, inferred, location may not meet map accuracy standard

Enumerated_Domain:

Enumerated_Domain_Value: F24

Enumerated_Domain_Value_Definition: Fault, high-angle, oblique slip, lnferred beneath mapped covering unit

Enumerated_Domain:

Enumerated_Domain_Value: F36

Enumerated_Domain_Value_Definition:

Fault, high-angle, oblique slip, existence questionable, location may not meet map 
accuracy standard

Enumerated_Domain:

Enumerated_Domain_Value: F54 standard

Enumerated_Domain_Value_Definition: Fault, high-angle, oblique slip, scarp, location meets map accuracy

Enumerated_Domain:

Enumerated_Domain_Value: GF9

Enumerated_Domain_Value_Definition: Geomorphic feature.ground-failure scarp.certain.may not meet map accuracy standard

Attribute:

Attribute_Definition: The features tagged GF9 in this report are scarps caused by groundwater withdrawal.

Enumerated_Domain:

Enumerated_Domain_Value: ML8

Enumerated_Domain_Value_Definition:

fissure.due to groundwater withdrawal and/or tectonics.certain.may not meet map accuracy

standard

Enumerated_Domain_Value_Definition_Source:

The miscellaneous linetype, ML8, has been added to lines.rel (included in the data package) but does not appear in the corresponding source USGS Open-file Report: Matti,

J.C., Powell, R.E., Miller, F.K., Kennedy, S.A., Ruppert, K.R., Morton, G.L., and

Cossette, P.M., 1997a, Geologic-line attributes for digital geologic-map databases produced by the Southern California Areal Mapping Project (SCAMP), Version 1.0: U.S.Geological Survey Open-File Report 97-861

Attribute:

Attribute_Definition:

Features tagged ML8 in this report are ground fissures caused by a combination of tectonic movements on faults of the San Jacinto Fault zone and groundwater withdrawal.

Attribute:

Attribute_Label: L-NAME

Attribute_Definition: Formal name of linear geologic feature

Detailed_Description:

Entity_Type:

Entity_Type_Label: LKVW_PTS.PAT

Entity_Type_Definition: Structural point data

Attribute:

Attribute_Label: P-DIP

Attribute_Definition: Dip of planar feature

Attribute:

Attribute_Label: P-STRIKE

Attribute_Definition: Azimuthal strike of planar feature

Attribute:

Attribute_Label: P-SYMB

Attribute_Definition:

Coded integer symbol that relates point to cartographic point symbol in markerset

(geoscamp2.mrk)

Attribute:

Attribute_Label: P-TAG

Attribute_Definition:

Coded alpha-numerical symbol that relates point to definition of point type in dictionary

look-up table (points.rel). For description of attributes in point classification dictionary,

refer to USGS Open-File Report 97-859 (see Entity_and_Attribute_Detail_Citation)

Attribute_Domain_Values:

Enumerated_Domain:

Enumerated_Domain_Value: B1

Enumerated_Domain_Value_Definition: Bedding attitude, sedimentary, horizontal

Enumerated_Domain: 
Enumerated_Domain_Value: B2

Enumerated_Domain_Value_Definition: Bedding attitude, sedimentary, inclined

Enumerated_Domain:

Enumerated_Domain_Value: B4

Enumerated_Domain_Value_Definition: Bedding attitude, sedimentary, vertical

Enumerated_Domain:

Enumerated_Domain_Value: B14

Enumerated_Domain_Value_Definition: Bedding attitude, sedimentary, inclined, indicated, not measured

Enumerated_Domain:

Enumerated_Domain_Value: FN4

Enumerated_Domain_Value_Definition: Foliation, inclined, indicated but not measured

Enumerated_Domain:

Enumerated_Domain_Value: FN13

Enumerated_Domain_Value_Definition: Foliation, igneous, inclined

Enumerated_Domain:

Enumerated_Domain_Value: FN14

Enumerated_Domain_Value_Definition: Foliation. igneous, vertical

Enumerated_Domain:

Enumerated_Domain_Value: FN42

Enumerated_Domain_Value_Definition: Foliation, metamorphic, inclined

Enumerated_Domain:

Enumerated_Domain_Value: FN43

Enumerated_Domain_Value_Definition: Foliation, metamorphic, vertical

Attribute:

Attribute_Label: P-DIPDIR

Attribute_Definition: Azimuthal direction of dip of planar feature

Attribute:

Attribute_Label: P-PLUNGE

Attribute_Definition: Plunge of linear feature

Attribute:

Attribute_Label: P-BEARING

Attribute_Definition: Azimuthal direction of plunge of linear feature

Detailed_Description:

Entity_Type:

Entity_Type_Label: LKVW_ANNO.AAT

Entity_Type_Definition: Annotation leaders and unit labels

Attribute:

Attribute_Label: L-SYMB

Attribute_Definition:

Coded integer symbol, value 1 , that relates arcs to cartographic line symbol in lineset geoscamp2.lin

Distribution_Information:

Distributor:

Contact_Information:

Contact_Organization_Primary:

Contact_Organization: U.S. Geological Survey Information Services

Contact_Address:

Address_Type: mailing

Address: Box 25286, Denver Federal Center

City: Denver

State_or_Province: Colorado

Postal_Code: 80255-0046

Country: USA

Contact_Voice_Telephone: 1-888-ASK-USGS

Contact_Voice_Telephone: 303-202-4700

Contact_Facsimile_Telephone: 303-202-4693 
Resource_Description: US Geological Survey Open-File Report 01-XXX

Distribution_Liability:

The U.S. Geological Survey (USGS) provides these geographic data "as is." The USGS makes no guarantee or warranty concerning the accuracy of information contained in the geographic data. The USGS further makes no warranties, either expressed or implied as to any other matter whatsoever, including, without limitation, the condition of the product, or its fitness for any particular purpose. The burden for determining fitness for use lies entirely with the user.

Although these data have been processed successfully on computers at the USGS, no warranty, expressed or implied, is made by the USGS regarding the use of these data on any other system, nor does the fact of distribution constitute or imply any such warranty.

In no event shall the USGS have any liability whatsoever for payment of any consequential, incidental, indirect, special, or tort damages of any kind, including, but not limited to, any loss of profits arising out of use of or reliance on the geographic data or arising out of delivery, installation, operation, or support by USGS.

This digital, geologic map database of the Lakeview 7.5'quadrangle, 1:24,000 map-scale, and any derivative maps thereof, is not meant to be used or displayed at any scale larger than 1:24,000 (e.g., 1:12,000).

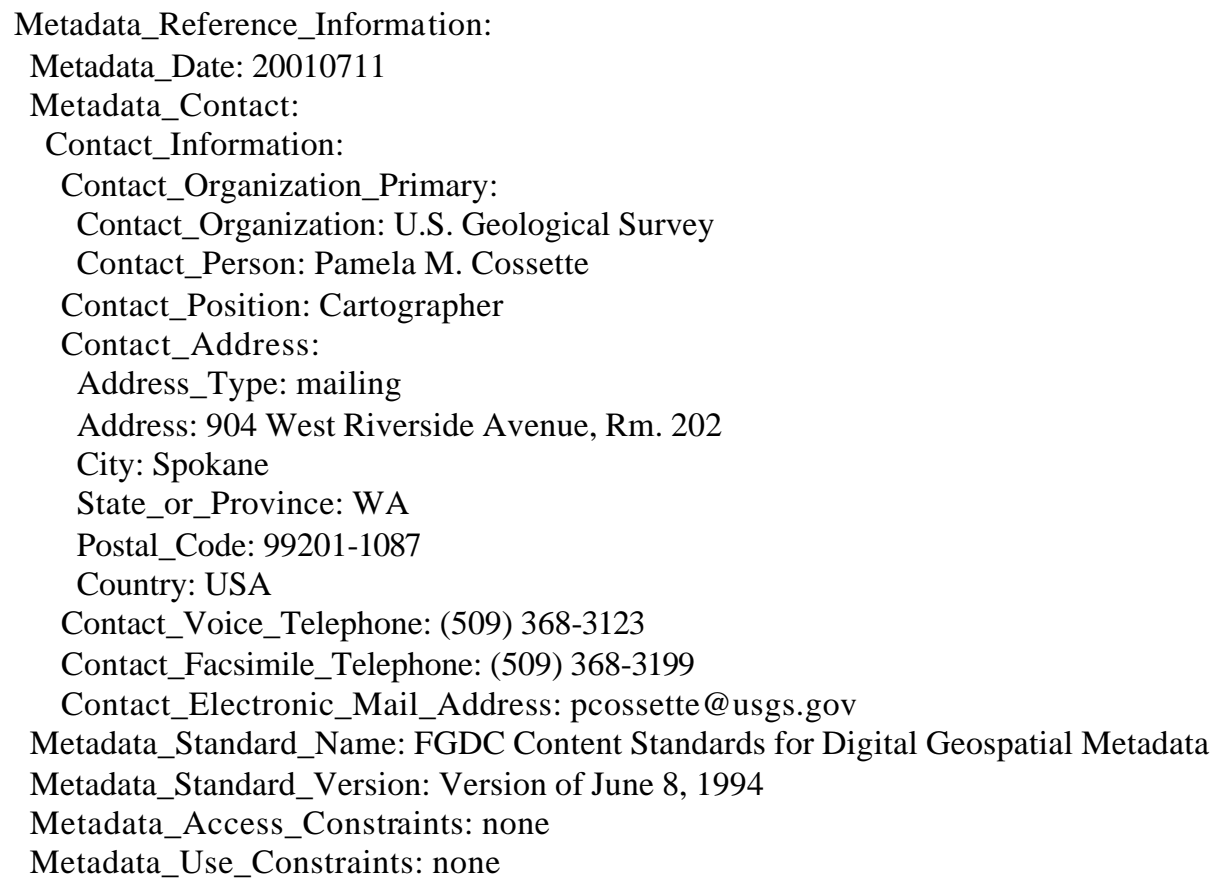

